\title{
O desafio das lideranças: assegurar a produtividade com pessoas de diferentes gerações
}

\section{The challenge of leadership: ensuring productivity with different generations of people}

\author{
Frederico Lopes Morais \\ Centro universitário UNA - Belo Horizonte - Minas Gerais - Brasil \\ fredpsic@hotmail.com \\ Iris Barbosa Goulart \\ Centro universitário UNA - Belo Horizonte - Minas Gerais - Brasil \\ irisbgoulart@gmail.com
}

\begin{abstract}
Resumo
As mudanças que ocorreram em todo o mundo a partir da segunda metade do século XX se tornaram responsáveis pelo desenvolvimento de características diferenciadas de cada uma das gerações que têm vivido a partir desta época. Um desafio que tem se apresentado para os líderes nas organizações tem sido conciliar sua atuação com as expectativas e necessidades de cada uma dessas gerações, garantindo que elas se relacionem de forma positiva e assegurem a produtividade no trabalho. Este artigo discute a possibilidade de se conciliar duas modalidades de atuação da liderança - a transacional e a transformacional, visando a influenciar trabalhadores de cada uma das gerações. Para isto, procede-se à identificação das características das gerações Baby Boomers, $\mathrm{X}$ e $\mathrm{Y}$ tal como são apresentadas na literatura e em pesquisas desenvolvidas no Brasil e busca-se caracterizar o modelo de liderança transacional e transformacional. A proposta do artigo é oportunizar a discussão sobre a necessidade de o líder organizacional desenvolver certa flexibilidade para manter as pessoas envolvidas com 0 trabalho, respeitando suas características individuais e pessoais.
\end{abstract}

Palavras-chave: gerações, liderança organizacional, liderança transacional, liderança transformacional, gestão organizacional.

\section{Abstract}

The changes that have occurred throughout the world from the second half of the 20th century became responsible for the development of differentiated characteristics of each of the generations that have lived from this season. A challenge that has been presented to the leaders in organizations has been reconcile their actions with the expectations and needs of each of these generations, ensuring they relate in a positive way and ensure productivity at work. This article discusses the possibility of reconciling two modalities of actuation of leadership - the transactional and transformational, aiming to influence employees of each of the generations. For this, it is the identification of the characteristics of the generations Baby Boomers, $X$ and $Y$ as are presented in the literature and in the research developed in Brazil and it aims at characterizing the model of transactional 
leadership and transformational. The proposed article is gradua the discussion on the need for the organizational leader develop a certain flexibility to keep people involved with the work, while respecting their individual characteristics and personal.

Keywords: generations, organizational leadership, transactional leadership, transformational leadership, organizational management.

\section{Introdução}

O termo organização tem sua origem no grego e significa "ferramenta" ou "aquilo através do qual se realiza uma atividade". Posteriormente foi incorporado ao latim organum, apresentando um conjunto de significados diferentes, com realce á idéia de que se trata "daquilo que funciona". Tanto em sua origem grega quanto latina, a palavra foi inicialmente utilizada para se referir ao sentido de organizar, de "dotar um organismo de uma estrutura coordenada" (OXFORD, 2002).

De acordo com Bastos e Peixoto (2015), foi a partir de 1880 que a palavra entrou para o vocabulário dos escritos políticos, adquirindo um novo sentido, passando a ser usada para descrever uma propriedade ou as características de uma sociedade ou de alguns grupos políticos. Nova interpretação se deu ao termo organização no século XIX quando em lugar de referir-se a uma propriedade de um grupo social, o termo passou a ser utilizado para se referir ao próprio grupo social, como um clube, uma sociedade esportiva, um grupo político.

No século XX, passou-se a falar de organização como o processo de organizar, ordenar, colocar um corpo organizado de pessoas de forma sistemática, atuando. Mesmo sob esta nova interpretação, a palavra organização tinha um caráter de certo modo estático, definindo um espaço onde o trabalho acontece: a empresa, o escritório, a indústria.

É novamente Bastos e Peixoto (2015) que apontam que o sentido atual da expressão organização - um corpo organizado de pessoas com um objetivo específico só vai se definir na sociedade a partir dos anos 1950, com o início dos estudos sistemáticos sobre as organizações, caracterizando a emergência de um campo específico de estudos: a teoria das organizações (BASTOS; PEIXOTO, 2015).

A partir da década de 1960, graças principalmente aos trabalhos conduzidos pelo sociólogo francês Georges Friedman, os estudos sobre as organizações se voltaram para os aspectos humanos das relações que se processam nas organizações. Nesse contexto, surgiram as pesquisas do francês Michel Crozier, que constituiu um dos primeiros grupos de estudo da Sociologia das Organizações (CHANLAT, 2006).

Foi também na França que surgiu o interesse pela constituição afetiva do pacto social e pelas diferentes relações que unem o indivíduo à organização. Nesse grupo de pesquisadores se incluem Max Pages, Eugene Enriquez, André Levy, Vincent de Gaulejac, Georges Lapassade, todos eles dedicados à análise psicossociológica.

Essas mudanças no sentido do termo organização apontam que atualmente ele tem ganhado um sentido dinâmico, uma vez que se refere a realidades socialmente construídas, no interior das quais a interação entre as pessoas é importante. Assim, podese definir organização como:

Um agrupamento social ou de indivíduos em interação. Organizações são criações ou ferramentas sociais, produtos de ações individuais e coletivas, sua dinâmica e seus processos entrelaçam-se com processos e dinâmicas de indivíduos e grupos em um espaço e tempo que delimitam e circunscrevem suas interações (BASTOS, 2001, p. 94) 
A partir dessa concepção dinâmica de organização, pesquisadores da área de Sociologia e Psicologia têm se dedicado a estudar as interações que se efetivam no ambiente do trabalho, dando especial ênfase à atuação da liderança. Bowditch e Buono (2014) consideram que as teorias sobre a liderança podem ser agrupadas em três categorias: a abordagem de traço, a perspectiva comportamental ou funcional e o ponto de vista situacional ou contingencial. Visando a buscar a forma de atuação mais adequada ao líder para gerenciar pessoas de diferenças gerações, este artigo privilegia a terceira categoria de estudos, que considera que a liderança é situacional, ou seja, o líder define seu comportamento conforme as circunstâncias. Uma das teorias que se fundamentam nesta perspectiva é a teoria de Bass e Avolio (2004), que aborda a liderança transacional e transformacional.

A partir de meados da década de 1990 uma nova tendência nos estudos sobre as interações no ambiente organizacional ganhou espaço - a coexistência de trabalhadores de diferentes gerações, verificando-se que cada uma delas apresenta características bem específicas. A relação que se estabelece entre as pessoas pertencentes a diferentes grupos etários e a autoridade tem sido objeto de várias pesquisas e diversas classificações têm sido propostas. Embora os limites inferiores e superiores de cada geração variem segundo os diferentes autores, a aproximação dos limites de cada uma das teorias propostas permite identificar as três gerações que constituem objeto deste estudo: a geração baby boomer, a geração $X$ e a geração $Y$.

A seguir, apresenta-se a teoria das gerações e comentam-se algumas pesquisas envolvendo tais grupos e seu comportamento característico.

\section{As gerações: conceito e características}

No século XXI, coexistem, no mundo do trabalho, pessoas de diferentes grupos etários, que disputam, no mesmo cenário, reconhecimento, carreira, prevalência de suas crenças, desenvolvimento profissional e oportunidade de exercerem cargos de liderança. Autores como Engelmann (2009), Oliveira, S. (2009), Osajima, Sternquiste e Manjeshwar (2010), Lombardia (2008) e Shah (2009) consideram que esses sujeitos pertencem a gerações que recebem as denominações de Baby Boomer, X, Y e Z.

Segundo Johnson (1997), vê-se que, em sentido mais amplo e menos preciso, uma geração é um conjunto de indivíduos nascidos aproximadamente na mesma época. O dicionário Houaiss (2012) define com mais precisão o que constitui uma geração: a) "conjunto de pessoas que têm aproximadamente a mesma idade"; b) "espaço de tempo correspondente ao intervalo que separa cada um dos graus de uma filiação, avaliado em cerca de vinte e cinco anos" (HOUAISS, 2012, p. 966).

Os estudos geracionais se iniciaram no século XIX, ligados à abordagem historiográfica, referindo-se principalmente às transformações sociais. Na primeira metade do século $X X$, Karl Mannheim trouxe uma das principais contribuições para a compreensão do conceito de gerações. Segundo ele, a sucessão geracional atinge todas as sociedades, uma vez que os atores nascidos em diferentes períodos históricos passam a conviver com o surgimento de novos agentes culturais e com o desaparecimento de outros. Logo, cada grupo geracional vivencia apenas em parte o período do processo histórico, fazendo suas interpretações a partir da experiência vivenciada e, nesse caso, surge à necessidade de as gerações anteriores transmitirem às novas gerações os bens culturais que foram acumulados por elas (MANNHEIM, 1993).

O ponto mais importante a ser notado é o seguinte: nem toda a situação de geração - nem mesmo todo grupo etário - cria novos impulsos coletivos e princípios formativos originais próprios, adequados à sua situação particular. Quando isso acontece, falaremos de uma realização das potencialidades inerentes a uma situação, e tudo indica que a frequência de tais realizações está 
estreitamente ligada ao ritmo de mudança social. Como resultado de uma aceleração no ritmo de transformação social e cultural, as atitudes básicas precisam se modificar tão rapidamente que a adaptação e modificação latente e contínua dos padrões tradicionais de experiência, pensamento e expressão deixam de ser possíveis, fazendo então com que as várias fases novas de experiência sejam consolidadas em alguma outra situação, formando um novo impulso claramente distinto e um novo centro de configuração (MANNHEIM, 1982, p. 92).

Mannheim (1993) considera a geração uma dimensão analítica importante para a compreensão da dinâmica das mudanças sociais e das formas de pensar e de agir de uma época. Para esse autor, as gerações constituem produtos específicos que podem produzir mudanças sociais, mas podem também constituir o resultado de uma mudança gestada pela geração anterior. Ele observa, ainda, que há um padrão temporal para formação de uma geração, que pode permanecer por dez ou quinze anos ou por vários séculos, como aconteceu no período feudal.

Dois pontos tornam a abordagem de Mannheim diferente da que é adotada por outros sociólogos: em primeiro lugar, sua posição contrária a períodos regulares para a definição dos cortes geracionais e, em segundo lugar, o fato de que ele leva em conta o movimento de sucessão das gerações, que estaria ligado à mudança social, ou seja, a dinâmica social se acelera com a ação de criação e transformação dos impulsos de gerações (TOMIZAKI, 2010).

Tomizaki (2010) trouxe outros elementos além da idade para a discussão do conceito de geração: a situação de classe, as experiências concretas e simbólicas comuns, a relação com outras gerações, a conjuntura histórica (social, econômica e política), as relações familiares e de parentesco. Ele considera que apesar da importância atribuída à idade, ela não é o elemento fundamental para a constituição de uma geração. A situação de classe tem também importância para a definição da geração, pois as pessoas que vivenciam um campo determinado tendem a desenvolver uma forma específica de pensar e de agir. Entretanto, para que esta situação tenha sentido, é necessário à influência de uma geração sobre a outra e verifica-se que uma geração não se constitui de modo independente e, por isto, a compreensão de uma geração deve adotar uma análise relacional.

Assim, é oportuno lembrar que, para se realizar uma análise geracional, o simples marco cronológico constitui apenas um ponto referencial, mas não serve como base para delimitar as formas de agir de um grupo etário. Assim, afirmar que um jovem pertence à Geração Y porque nasceu entre 1978 ou 1982 é simplificar o conceito e a compreensão da idéia de Geração; seria preciso reconhecer os fatos históricos marcantes para aquela época em que ele viveu. Apesar do alerta sobre essa limitação, a dificuldade de se definir um marco para a definição de cada geração faz com que, nesta pesquisa, o critério cronológico seja adotado para agrupar os sujeitos que compõem a amostra.

A geração Baby Boomer é constituída pelas pessoas nascidas no período compreendido entre as décadas de 1940 e 1960, período de crescimento econômico, no final e após a segunda Guerra Mundial; por isso, os membros desta geração idealizavam atuar na reconstrução de um novo mundo pós-guerra (OLIVEIRA, S. 2009). Existem variações e divergências entre autores nas datas propostas para esta geração: Shah (2009); Osajima, Sternquist e Manjeshwar (2010), consideram que são os nascidos entre 1941 a 1960 e para Engelmann (2009), são pessoas nascidas entre 1943 a 1963, durante o Baby Boom.

A população correspondente a esta geração se encontra concentrada nos países ocidentais e, segundo Hudson (2010), devido ao seu tamanho e espaço temporal, os indivíduos a ela pertencentes tiveram um profundo impacto da sociedade americana. Alguns dos acontecimentos marcantes como o rock na droll, a corrida espacial e a independência das mulheres no mercado de trabalho marcaram a geração Baby Boomer, 
moldando sua personalidade com traços de otimismo e idealismo. Para essa geração, trabalho e sacrifício são os geradores de bons resultados financeiros (GLASS, 2007; OSAJIMA; STERNQUIST; MANJESHWAR, 2010).

Durante sua trajetória, essa geração foi educada para competir, com muita disciplina, ordem e respeito pelos outros; essas qualidades não foram consideradas ou apreciadas nos anos subsequentes, como aponta Conger (1998). Essas pessoas foram educadas com rigidez e seguiam regras padronizadas em relação à disciplina e à obediência. São indivíduos que não se abrem muito para o questionamento e a principal preocupação está na busca pela estabilidade no emprego; colocam a carreira acima de tudo e se adaptam em qualquer organização (CONGER,1998).

No que se referem às questões profissionais, os participantes dessa geração foram educados em um ambiente corporativo no qual a liderança era sinônimo de controle, focando sempre os resultados e mantendo um alinhamento e um compromisso com a missão da empresa, valorizando o status e a ascensão profissional (OLIVEIRA, S. 2009). Nesse ambiente, estão mais motivados, são otimistas e workaholics. Procuram oportunidades de inserção econômica no campo do trabalho e aplicam seus esforços escolares em carreiras que prometam facilidades, na busca de posições garantidas no universo empresarial (SANTOS et al., 2011).

Os BabyBoomers de acordo com Kanaane (1999), aplicaram as habilidades e competências escolares em carreiras que oportunizavam posições elevadas, ou mesmo garantias e segurança para o futuro. Valorizam o status e a ascensão profissional dentro da empresa, à qual são leais.

A definição cronológica da geração $X$ também varia conforme os autores, oscilando seu início entre 1960 (OLIVEIRA, S., 2009) e 1964 (ENGELMANN, 2009) e seu final entre 1976 e 1980. Esta geração advém de um momento de revolução e de luta política e social, inclui pessoas que presenciaram a Guerra Fria, a queda do muro de Berlim, a Síndrome da Imunodeficiência Adquirida (AIDS) e a modificação de conceitos impostos pela sociedade anterior (SANTOS et al., 2011).

Este grupo traz como característica o controle da natalidade e a decisão de ter famílias menores. Adultos desta geração presenciaram a recessão da década de 1980, em que ocorreram demissões em massa nas empresas ocidentais. Por isto, uma de suas características é o consumo consciente de produtos e serviços aliados a um comportamento mais céptico, menos fiel, e mais independente que a geração anterior (GLASS, 2007).

Oliveira, S. (2009) também pontua que essa geração foi totalmente influenciada por programas de televisão, tanto no que diz respeito à educação, quanto à rotina familiar. Tal influência também envolveu um aumento exacerbado dos apelos consumistas, reordenando e orientando o modo de viver e agir das pessoas. O autor destaca que essa geração presenciava, nos movimentos estudantis e "hippies", uma forma de manifestar suas insatisfações.

Para Lombardia (2008), as inovações tecnológicas avançaram significativamente deixando grandes marcas na juventude da época, favorecendo a aceleração das atividades diárias, promovendo manifestações revolucionárias e qualificando estilos de vida diferenciados. Os jovens organizavam manifestações em movimentos estudantis que buscavam, por exemplo, direitos iguais para todos. A música servia para representar os valores e posições políticas, outrora marcadas pela censura de imprensa, e a liberdade de escolha passou a ser característica marcante dessa geração.

Os membros desse grupo preferiram as áreas de administração e economia, trocando o idealismo por um realismo mais pragmático e cético (LOMBARDIA, 2008). Valorizam o trabalho e a estabilidade financeira, na condição de garantir a realização de desejos pessoais e materiais. Segundo Oliveira (2009), essa geração é marcada pelo 
pragmatismo e autoconfiança nas escolhas, e busca promover a igualdade de direitos e de justiça em suas decisões.

No segmento profissional, os sujeitos da geração $X$ costumam ser profissionais de alto nível, motivados pelas perspectivas de carreira como forma de manutenção de seu poder socioeconômico, mas são considerados egoístas e hedonistas. Segundo Lombardia (2008, p. 4), as pessoas pertencentes a essa geração "são conservadoras, possuem aversão à supervisão, desconfiam de verdades absolutas, são positivistas, autoconfiantes e cumprem objetivos, não os prazos".

Conforme Oliveira, S. (2009), as pessoas desta geração apresentam um comportamento mais independente e mais empreendedor, focando as ações em resultados. Irmãos mais novos das pessoas da geração do baby boom, os integrantes da geração $X$ têm quatro proeminentes traços de caráter com implicações no local de trabalho de nossos dias: (1) buscam um equilíbrio real entre trabalho e vida pessoal; (2) são profundamente independentes, seguindo os passos de seus antecessores imediatos; (3) são a primeira geração que verdadeiramente domina os computadores e representa a Era da Informação e (4) sonham com locais de trabalho que lembrem comunidades.

A geração $Y$ é constituída por filhos da geração Baby Boomers e dos primeiros membros da geração X; segundo Lombardia (2008), são nascidos entre 1980 e 2000; para Shah (2009) e Osajima, Sternquist e Manjeshwar (2010) são os nascidos entre 1977 e 1992; para Engelmann (2009), são os que nasceram entre 1978 e 1994.

Oliveira, S. (2009) observa que esta geração não passou por nenhuma grande ruptura social, vive a democracia, a liberdade política e a prosperidade econômica. É conhecida como a geração dos resultados, tendo em vista que nasceu na época das tecnologias, da Internet e do excesso de segurança. Os membros da geração $Y$ cresceram em contato com as tecnologias de informação e são mais individualistas; defendem suas opiniões e priorizam o lado pessoal em relação às questões profissionais (OLIVEIRA, 2009).

As pessoas dessa geração são consideradas ambiciosas, individualistas, instáveis, todavia, preocupadas com o meio ambiente e com os direitos humanos. Tendem a fazer várias coisas ao mesmo tempo, gostam de variedade, desafios e oportunidades. Para Loiola (2009), outra característica marcante das pessoas da geração $Y$ é que aceitam a diversidade, convivem muito bem com as diferenças de etnia, sexo, religião e nacionalidades em seus círculos de relação.

Segundo Oliveira, S. (2009), as pessoas dessa geração valorizam menos a permanência em uma única empresa e mantêm mais lealdade a si mesmas; porém, são mais fáceis de serem recrutadas, uma vez que buscam trabalhar com liberdade, flexibilidade e criatividade, sentindo, ainda, necessidades de avaliações contínuas. Raines (1997) acrescenta que, como profissionais, possuem o desejo de trabalhar e aprender, não demonstrando medo do risco de demissão, fator que faz com que busquem o máximo de conhecimento das empresas nas quais estão atuando em determinado momento.

A geração $Y$ é conhecida como a "geração da internet, da variedade, das tecnologias que mudam contínua e vertiginosamente" (LOMBARDIA, 2008, p. 3). Viveram e vivem num outro contexto político social sem grandes transformações e rupturas sociais. Os sujeitos da geração $Y$ são silenciosos e contundentes, parecem saber exatamente o que querem. Eles não reivindicam: executam a partir de suas decisões, dos blogs e dos SMS (LOMBARDIA, 2008). Não polemizam nem pedem autorização: agem.

$O$ alto nível de formação dos indivíduos da geração $Y$ os torna, também, mais decididos. Sua atitude diante da hierarquia é cortês, mas não de estrito respeito ou amor/ódio, como a das gerações anteriores. Completam o perfil desta geração, segundo Lombardia (2008): com frequência são filhos únicos ou tem poucos irmãos; cerca de 91,6\% desses jovens são usuários da internet, e estão acostumados com o "bombardeio de imagens"; não desenvolveram a paciência - seus desejos devem ser satisfeitos aqui e 
agora; focam no curto prazo. Trata-se, portanto, de uma geração de resultados, não de processos.

\section{Liderança e Gestão nas Organizações}

A pesquisa sobre liderança tem se desenvolvido desde a década de 1930 nos campos da Psicologia social e do comportamento organizacional, como afirmam Bowditch e Buono (2014). Estimulados pelo surgimento da Teoria de Relações Humanas, os estudos sobre este tema evoluíram das teorias de traço para a identificação das funções básicas que descrevem o que os líderes devem ser até as teorias contingenciais. As teorias de traço admitem que algumas pessoas possuem características de personalidade que as levam a exercer de forma diferenciada a liderança. Essas características dizem geralmente ao respeito e ao nível de inteligência, capacidade de comunicação, relacionamento interpessoal.

As teorias que se detêm na identificação das funções básicas que descrevem a atuação do líder compõem a perspectiva comportamental ou funcional e incluem um significativo número de estudos. Neste grupo incluem-se os estudos de Kurt Lewin, iniciados no Massachussets Institute of Technology (MIT) sobre estilos de liderança democrática, autocrática e laissez faire, por volta da década de 1940 e foram continuados por pesquisadores da Ohio State University e da Universidade de Michigan. Esses estudos se referem aos comportamentos esperados do líder e assumiram formas que sugeriam a necessidade de se preparar os gestores para o exercício da liderança, como a Grade Gerencial (Managerial Grid) proposta nos anos 1960 por Robert Blake e Jane Mouton e a Teoria dos Elos de Ligação (linking pins) proposta por Rensis Likert (BOWDITCH; BUONO, 2014).

Mais recentemente, a partir da década de 1970, a crítica feita às teorias comportamentais apontou as situações que emergem nas relações entre as pessoas como capazes de influenciar a liderança. Surgiram, então, as teorias contingenciais ou situacionais. Entre elas, merecem destaque a teoria situacional de Hersey e Blanchard, usada no treinamento de empresas como a IBM, Mobil Oil e Xerox e no serviço militar dos Estados Unidos; a teoria Caminho-objetivo, proposta por Robert House, a teoria da Troca Líder-Membro (TLM) desenvolvida por George Graen e a teoria de Participação - lider, surgida em 1973 e desenvolvida por Victor Vroom e Philip Yetton e posteriormente revista por Vroom e Arthur Jago (ROBBINS, 2014).

Os teóricos da contingência argumentam que as pessoas que ocupam cargos de liderança podem ter sua eficácia determinada pela sua capacidade de adaptarem sua atuação às exigências de determinada situação (BOWDITCH; BUONO, 2014, p. 161). Esses mesmos autores sugerem que geralmente se pensa que o gestor é um membro da organização com poder legítimo (autoridade) para dirigir as atividades relacionadas ao trabalho de pelo menos um subordinado e nesse contexto é visto como um líder. Eles realçam, ainda, que mesmo na visão tradicional da liderança os gestores planejam, organizam, conseguem auxiliares, dirigem, controlam e coordenam.

Mintzberg (2001) empreendeu uma série de observações sobre as atividades diárias de gestores de alto escalão e descobriu que as ações desses profissionais tinham a ver com atividades além do planejamento, controle, contratação de funcionários e outras atividades de gestão. Para ele, o trabalho dos gestores tinha a ver com relacionamentos interpessoais, com a transferência de informação e com a tomada de decisão.

Kotter (1999) aprofundando este estudo estabeleceu uma distinção entre o papel dos gestores e dos líderes. Para ele, enquanto a gestão trata de como lidar com a complexidade, a liderança trata de como lidar com a mudança. Logo, nessa perspectiva, a liderança lida com o controle, alocando os recursos para atingir os objetivos da organização, estabelecendo prioridades, projetando trabalho e alcançando resultados, a 
liderança trata de criar uma visão compartilhada, manter os trabalhadores motivados, para que contribuam para essa visão e incentivando-os a alinharem seus interesses com os interesses organizacionais.

O que se tem verificado é que na atualidade o complexo mundo organizacional exige tanto uma liderança forte quanto uma gestão forte e o que se espera é que a combinação desses dois aspectos habilite os gestores a atingirem os objetivos organizacionais, mantendo os funcionários motivados e encaminhando a adaptação às mudanças.

Nesse contexto de atendimento à demanda de produtividade e de adequação às mudanças, surgiu a referência a dois estilos de liderança: transformacional e transacional, que podem auxiliar o gestor a exercer o papel de líder. Resultado da evolução de diversos estudos teórico-empíricos Downton (1973), House (1977), Zaleznik (1977), Burns (1978), Bass (1985) introduziu sua teoria sobre liderança, a qual foi posteriormente enriquecida pela associação de suas idéias iniciais com as contribuições de Avolio.

Avolio e Bass (1991) não consideram que os dois estilos - transacional e transformacional constituam os extremos de uma orientação dos líderes e admitem que os bons gestores devem combinar os dois estilos.

A liderança transacional é focada no reconhecimento dos processos de desempenho do trabalhador. Assim, as necessidades e desejos dos subordinados são satisfeitos e reconhecidos, se eles desenvolverem esforços para realizarem as tarefas. Portanto, de acordo com Bass (1999, p. 10) "a liderança transacional se refere às trocas entre o líder e os subordinados para responder aos seus próprios interesses". Esta motivação produz energia e encaminha a pessoa para o alcance dos objetivos previstos. Esta abordagem é caracterizada pelo reforço contingente positivo e negativo e adéqua-se a treinamentos de primeira ordem. No ambiente militar, os elogios, a recompensa, 0 recurso ás punições previstas nos regulamentos constituem formas de encaminhar os subordinados ao alcance da missão. A recompensa é contingente se o subordinado desempenhar seu papel e realizar as tarefas previstas.

Bass (1998) aponta que na forma construtiva de exercer o estilo transacional o líder trabalha realizando negociações, buscando o entendimento mútuo e esclarecendo como será a recompensa se os resultados forem alcançados. Na forma coercitiva, este estilo de liderança estabelece uma monitoração dos objetivos, esperando ou antecipando a ocorrência de erros e desvios à norma estabelecida.

A teoria sobre liderança transformacional sugere que os líderes devam usar processos de influência superiores aos que são usados pelos que adotam estilo transacional. Eles não se limitam a reagir aos problemas tal como os recebem, mas procuram construir objetivos coletivos. Bowditch e Buono (2014) consideram que os líderes transacionais são suficientes pra uma era de mercado em expansão contínua e competição estrangeira inexistente. Entretanto, esses autores observam que no atual ambiente de negócios, quando a liderança enfrenta um mundo turbulento e muitas vezes caótico, os líderes fortes precisam criar processos eficazes de mudança interna, que capacite suas organizações a conseguirem lidar com a mudança externa.

Kotter (1999) realça, nesse caso, a necessidade de criar um senso de urgência por meio da identificação de crises e oportunidades; construir uma coalizão norteadora dos membros da organização para conduzir a mudança; desenvolver uma visão para direcionar o esforço e as estratégias para conduzir a mudança; desenvolver uma visão para direcionar o esforço e as estratégias de mudança; delegar poder e incentivar a assunção de riscos; consolidar ganhos e revigorar o processo; recompensar as pessoas que atingirem as realizações; fixar novas abordagens na cultura da organização.

Os líderes transformacionais têm uma perspectiva diferente dos transacionais; são considerados mais visionários, figuras inspiradoras absortas por ideais e metas, específicos e capazes de provocar intensas emoções nos seguidores. Eles têm tanto a 
capacidade de articular e transmitir uma visão que identifique as metas superordenadas para uma organização quanto o carisma para dar energia e motivação para que as pessoas alcancem metas mais amplas (BOWDITCH; BUONO, 2014).

O conceito de liderança transformacional tem sido discutido desde 1985, nos primeiros escritos de Bass e em 2004, Bass e Avolio propuseram uma nova abordagem, que vem sendo apresentada como uma teoria full range de liderança. Eles passaram a considerar que o comportamento de liderança variava ao longo de um continuum de liderança laissez faire (ausência de intervenção do líder) para a liderança transacional até a liderança transformacional.

Nessa perspectiva, Bass e Avolio (2004) sugeriram que os líderes transformacionais têm como objetivo mudar a forma como os subordinados se percebem, enfatizando as oportunidades e os desafios que o meio lhes apresenta. Os líderes transformacionais são, segundo esses autores, vistos como indivíduos pró-ativos, que se empenham em otimizar o desenvolvimento e a inovação do indivíduo, do grupo e da organização. Através da influência idealizada, da estimulação intelectual ou da consideração individualizada, esses líderes permitem que os subordinados ultrapassem os seus próprios interesses. Bass (1999) já havia afirmado que os líderes transformacionais elevam os ideais e o nível de maturidade dos subordinados, bem como as necessidades de realização, autoatualização e bem estar dos indivíduos, da organização e da sociedade.

Em síntese, o processo de liderança deve integrar, por um lado, o sentido de autorealização individual e, por outro, o sentido de eficácia coletiva, motivando os subordinados com vista a atingir o compromisso e o envolvimento com as tarefas (OLIVEIRA, J. F., 2009).

Popper e Mayseless (2002) concentram sua análise do processo transformacional centrando-se na estrutura psicológica dos líderes transformacionais. Eles observam que as pessoas que têm como dominante o estilo transformacional apresentam algumas características bem definidas: a primeira dessas características é o desejo de influenciar e ser autoeficaz; a segunda característica é que esses líderes são indivíduos com capacidade e desejo para doar, o que evidencia preocupação com os outros; a terceira característica é que os líderes transformacionais são pessoas otimistas e a quarta característica se refere a um elevado nível de curiosidade e abertura á experiência. Em suma, esses autores defendem o ponto de vista de que líderes transformacionais têm uma estrutura psicológica com tendência à ascendência social, crença na capacidade de influenciar as pessoas, motivação e habilidade para tratar os outros de modo positivo e encorajador.

A título de conclusão, pode-se inferir que a liderança transacional e a transformacional são dois modelos que se complementam. "A liderança transformacional é construída sobre a liderança transacional e produz nos liderados níveis de esforço e de desempenho que vão além dos obtidos apenas na abordagem transacional" (ROBBINS, 2014, p. 319). Entretanto, esses estilos podem ser mais eficazes em situações distintas: enquanto o líder transformacional consegue melhores resultados em períodos de fundação organizacional e de mudança, o líder transacional tem melhor desempenho em fases de evolução lenta e em ambientes relativamente estáveis. A liderança transformacional transforma os liderados no sentido de eles passarem a perseguir os objetivos da organização, deixando os seus próprios interesses em segundo plano, enquanto a liderança transacional resulta numa atenção às necessidades e desejos dos liderados, levando-os a buscarem esses interesses e alcançarem os objetivos organizacionais. 


\section{4. $O$ desafio de liderar diferentes gerações}

Como foi mencionado no início deste artigo, as organizações convivem no século $\mathrm{XXI}$, com pessoas de diferentes gerações, e este tema tem sido abordado por autores como Engelmann (2009), Oliveira, S. (2009), Osajima, Sternquist e Manjeshwar (2010), Lombardia (2008) e Shah (2009).

O grande desafio que tem se apresentado para os gestores consiste em adotar um modelo de liderança que mobilize essas pessoas, marcadas por diferenças históricas e socialmente construídas, a assumirem comportamentos que se prestem ao alcance dos objetivos organizacionais.

Bowditch e Buono (2014), assim como Robbins (2014) consideram um ponto de partida relevante, que tem sido a abordagem contingencial de liderança, segundo a qual os gestores devem se preparar para as demandas que emergem, buscando compreender as pessoas, a complexidade da situação e adotando comportamentos que os levem a influenciar os trabalhadores.

As teorias contingenciais têm se multiplicado nos últimos anos, e dentre elas tem merecido especial atenção no mundo acadêmico e empresarial a teoria que vem sendo desenvolvida por Bass e Avolio (1985, 1999) Avolio e Bass (1991), e Bass e Avolio (2004). Sem colocar os modelos de liderança transacional e transformacional como opostos, os autores sugerem duas formas de manter os liderados motivados para o alcance dos objetivos organizacionais. Essas maneiras diferenciadas de se atingir os objetivos organizacionais apontam ora para as necessidades das pessoas, que precisam ser reconhecidas e recompensadas, ora para a os objetivos organizacionais, que precisam tornar-se significativos para os trabalhadores.

Conger (1998) relatou que as pessoas da geração baby boomer foram educadas para competir, com disciplina, ordem e respeito pelos outros; submetem-se a regras padronizadas em relação à disciplina e à obediência, e têm como preocupação a estabilidade no emprego. Considerando-se as características dessas pessoas, pode-se inferir que o gestor tem melhores condições de envolvê-las com os objetivos organizacionais, tornando-as mais identificadas e comprometidas com a organização. Oliveira, S. (2009) confirma essas características, observando que essas pessoas focam o resultado e mantêm um alinhamento com a missão da empresa, valorizando o status e a ascensão profissional. Nesse caso, a adoção do modelo de liderança transacional pode levar a resultados mais produtivos do trabalho, além de manter as pessoas mais motivadas, estabelecendo um vínculo mais estreito com a organização.

Lombardia (2008), Shah (2009) e Oliveira, S. (2009) consideram que as pessoas da geração X são marcadas pelas inovações tecnológicas, pela aceleração das atividades diárias num mundo em mudança, assim como pela a liberdade de escolha, que passou a ser característica marcante dessa geração. Os membros da geração $X$ tendem a valorizar o trabalho e a estabilidade financeira, na condição de garantir a realização de desejos pessoais e materiais. Ainda de acordo com esses autores, os sujeitos da geração $X$ são motivados pelas perspectivas de carreira, são autoconfiantes e cumprem seus objetivos. Uma boa combinação de estilos de liderança transacional e transformacional poderia, provavelmente, encaminhar essas pessoas, na medida em que seus objetivos pessoais pudessem ser combinados com os objetivos das organizações, uma vez que eles buscam um equilíbrio entre o trabalho e a vida pessoal.

Os membros da geração Y, por sua vez, são caracterizados por Lombardia (2008), como sendo os nascidos entre 1980 e 2000; para Shah (2009), Osajima, Sternquist e Manjeshwar (2010) como aqueles que não enfrentaram uma grande ruptura social e cresceram num ambiente seguro, em contato com as tecnologias de informação. Eles tendem a ser mais individualistas; defendem suas opiniões e priorizam o lado pessoal em relação às questões profissionais, como afirma Oliveira (2009). 
Loiola (2009) e Oliveira, S. (2009) apontam em suas pesquisas que essas pessoas são geralmente ambiciosas, individualistas, gostam de variedade, desafios e oportunidades. Provavelmente, por este motivo, elas não se prendem muito ao emprego e não iniciam sua vida profissional aspirando continuar na mesma organização por muito tempo. Nesse caso, a adoção de um modelo de liderança transformacional pode levar a melhores resultados quando o gestor aspira influenciar os membros da geração Y para um trabalho. Na medida em que valoriza as características dessas pessoas, busca conhecer seus objetivos e necessidades e se envolve com a dinâmica do grupo desses jovens o gestor pode obter o envolvimento delas com o trabalho.

Nas últimas décadas, o estudo do modelo mais efetivo de liderança tem sido um tópico muito investigado (OLIVEIRA, J. F., 2009). Dando-se ênfase ao caráter contingencial da liderança, os resultados dos estudos têm apontado que os melhores gestores são aqueles que adotam tanto a liderança transacional quanto a transformacional. É indispensável que o gestor seja capaz de avaliar em qual situação e com qual grupo de pessoas a predominância de um desses modelos pode levar a melhores resultados tanto no nível individual, como a satisfação no trabalho, o compromisso organizacional e o desempenho, mas também a nível organizacional, tratando-se da dinâmica do grupo e dos resultados almejados pela organização.

\section{Referências}

AVOLIO, B. J.; BASS B. M. The full range leadership development programs: Basic and advanced manuals. Binghamton, NY: Bass, Avolio e Associates, 1991.

BASS, B. M. Leadership and performance beyond expectations. New York: The Free Press. 1985.

BASS, B. M. Transformational leadership: Industrial, military, and educational impact. Mahwah, NJ: Lawrence Erlbaum Associates, Inc. 1998.

BASS, B. M. Two decades of research and development in transformational leadership. European Journal of Work and Organizational Psychology, New York, v. 8, n. 1, p. 932, mar. 1999.

BASS, B. M.; AVOLIO, B. J. MLQ. Multifactor leadership questionnaire. Edwood City: Mind Garden, 2004

BASTOS, A. V. Cognição e ação nas organizações. In: DAVEL, E.; VERGARA, S. C. (Org.). Gestão com pessoas e subjetividade. São Paulo: Atlas, 2001, p.79-113.

BASTOS, A. V. B.; PEIXOTO, A. L. A. Organizações. In: BENDASSOLLI, P. F; BORGESÁNDRADE, J. E. (Org.). Dicionário de psicologia do trabalho e das organizações. São Paulo: Casa do Psicólogo, 2015.

BOWDITCH, J. L.; BUONO, A. F. Fundamentos de comportamento organizacional. 6. ed. São Paulo: LTC, 2014.

CHANLAT, J. F. Análise das organizações: panorama da produção em língua francesa contemporânea (1950-2000). In: CHANLAT, J. F; FACHIN, R.; FISCHER, T. (Org.). Análise das organizações - perspectivas latinas: olhar histórico e constatações atuais. Porto Alegre: UFRGS, 2006. 
CONGER, J. Quem é a geração X?HSM Management. n. 11, p. 128-138, nov./dez. 1998.

DOWNTON, J. Leadership: Commitment and Charisma in the Revolutionary Process. New York: The Free Press, 1973.

ENGELMANN, D. C. O Futuro da Gestão de Pessoas: como lidaremos com a geração Y?. 2009. Disponível em: <http://www.rh.com.br> Acesso em Abril de 2012.

GLASS, A. Understanding generational differences for competitive success. Industrial and Commercial Training, v. 39, n. 2, p. 98-103, mar. 2007.

HUDSON, S. Wooing zoomers: marketing to the mature traveler. Marketing Intelligence e Planning, v. 28, n. 4, p. 444-461, june. 2010.

HOUAISS, A. Dicionário Houaiss da língua portuguesa, 2. ed. Rio de Janeiro: Editora Objetiva, 2012.

HOUSE, R. J. A. 1976 theory of charismatic leadership. In: HUNT, J. G.; LARSON, L. L. (Org.). Leadership: The cutting edge. Carbondale: Southern Illinois University Press, 1977.

JOHNSON, A. G. Dicionário de sociologia: guia prático da linguagem sociológica. Tradução: Ruy Jungmann; consultoria, Renato Lessa. Rio de Janeiro: Jorge Zahar, 1997, p. 116.

KANAANE, R. Comportamento humano nas organizações: o homem rumo ao século XXI. 2. ed. São Paulo: ATLAS, 1999. p. 36-55.

LOIOLA, R. Geração Y. Revista Galileu, São Paulo, n. 219, p. 50-53, out. 2009. Disponível em: <http://www.professores.uff.br/screspo/PSI P2 artigo9.pdf>. Acesso em Abril. 2012.

LOMBARDIA, P. G. Quem é a geração Y?. HSM Management, n. 70, p. 1-7. set./out. 2008.

KOTTER, J. P. Liderando mudança. Rio de Janeiro: Campus, 1999

MANNHEIM, K. Sociologia. São Paulo: Ática, 1982. p. 80.

MANNHEIM, K. El problema de las generaciones. Revista Española de Investigaciones Sociológicas, n. 62, p. 145-16, 1993.

MINTZBERG, H.; QUINN, J. B. O processo da estratégia. 3. ed. Porto Alegre: Bookman, 2001.

OLIVEIRA, J. F. Profissão líder: desafios e perspectivas. São Paulo: Saraíva, 2009.

OLIVEIRA, S. Geração y: era das conexões, tempo de relacionamentos. São Paulo: Clube de Autores, 2009. 
OSAJIMA, K.; STERNQUIST, B.; MANJESHWAR, S. Japanese Materialism: a Comparison between the New Breed and Second Baby-boomer Age-cohorts. Journal of Asia Business Studies, v. 4, n. 2, p. 57-72, may. 2010.

OXFORD. The oxford english dictionary. Oxford, United Kingdom: Oxford University Press, 2002.

POPPER, M.; MAYSELESS, O. Internal world of transformational leaders. In: AVOLIO. B.; YAMMARINO, F. (Org.). Transformational and charismatic leadership: The road ahead, 2. ed. Oxford: Elsevier Science, 2002.

RAINES, C. Beyond generation $\mathbf{x}$ : a practical guide for managers. Califórnia: Crisp Publications Incorporated, 1997.

ROBBINS, S. Comportamento organizacional. Tradução Christina Ávila de Menezes. 13. ed. São Paulo: LTC Editora, 2014.

SANTOS, C. F.; ARIENTE, M.; DINIZ, M. V. C.; DOVIGO, A. A. O processo evolutivo entre as gerações $x$, y e baby boomers. In: SEMINÁRIO EM ADMINISTRAÇÃO, 14., 2011, São Paulo. Anais... São Paulo: XIV SEMEAD, 2011.

SHAH, G. The impact of economic globalization on work and family collectivism in India. Journal of Indian Business Research, v. 1, n. 2/3, p. 95-118, june 2009.

TOMIZAKI, K. Transmitir e herdar: o estudo dos fenômenos educativos em uma perspectiva intergeracional. Educação e Sociedade, Campinas, v. 31, n.111, p. 327-346, abr./jun., 2010.

ZALEZNIK, A. Managers and leaders: Are they different?. Harvard Business Review, v. 55, n. 5, p. 67-78, may/june 1977. 